\title{
Immunoglobulin and Iron Deficiency Anemia
}

\author{
Viroj Wiwanitkit
}

Received: 2 November 2010/ Accepted: 14 April 2011/Published online: 8 May 2011

(C) Indian Society of Haematology \& Transfusion Medicine 2011

I read the recent publication on immunoglobulin and iron deficiency anemia with a great interest [1]. Sadeghian et al. [1] concluded that "serum immunoglobulin levels did not change in iron deficiency anemia." This report is concordant with some previous reports such as the reports by Bagchi et al. [2]. However, there are some basic facts to be addressed. First, the iron deficiency anemia can be due to several etiologies. In case that the anemia is the result from hookworm infestation, the change of the immunoglobulin, especially for immunoglobulin A, should be observed [3]. In the report, there is no complete clarification of the iron deficiency anemia based on the exact etiologies. Second, the problems on quality control of the laboratory investigation for the immunoglobulin level should be mentioned.

\section{References}

1. Sadeghian MH, Keramati MR, Ayatollahi H, Manavifar L, Enaiati H, Mahmoudi M (2010) Serum immunoglobulins in patients with iron deficiency anemia. Indian J Hematol Blood Trans 26:45-48

2. Bagchi K, Mohanram M, Reddy V (1980) Humoral immune response in children with iron-deficiency anaemia. Br Med J 280(6226):1249-1251

3. Bungiro RD Jr, Sun T, Harrison LM, Shoemaker CB, Cappello M (2008) Mucosal antibody responses in experimental hookworm infection. Parasite Immunol 30(5):293-303

V. Wiwanitkit $(\bowtie)$

Wiwanitkit House, Bangkhae, Bangkok 10160, Thailand

e-mail:wviroj@yahoo.com 